Copyright (C) 2021 by Academic Publishing House Researcher s.r.o.

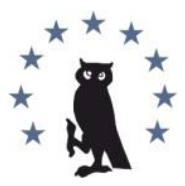

Published in the Slovak Republic Media Education (Mediaobrazovanie)

Has been issued since 2005

ISSN 1994-4160

E-ISSN 2729-8132

2021. $17(3): 485-495$

DOI: $10.13187 / \mathrm{me} .2021 .3 .485$

www.ejournal53.com

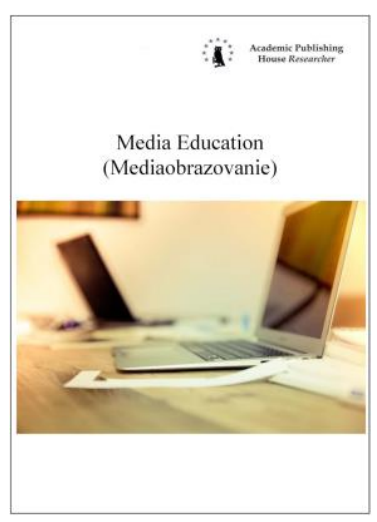

\title{
Investigating the Quality of Data Using Situated Learning Theory and Communication Mediation Model: PLS-SEM Approach to Estimate the Reliability and Validity of the Constructs
}

\author{
Sumera Memon a, Muhammad Ramzan Pahore ${ }^{b},{ }^{*}$, Sana Shahid a \\ a DMCS, Sindh Madressatul Islam University, Karachi, Pakistan \\ b DMCS, University of Sindh, Jamshoro, Pakistan
}

\begin{abstract}
This article examines the reliability of the instruments by using Partial Least Squares PLS and determined the convergent validity and discriminant validity of the latent variable under study. Specifically, the suggestion for applying PLS-SEM in media and communication studies have followed to prove the potentials of PLS-SEM using 228 datasets. Hence, the current study involves 7-constructs, 51-item which were adopted and adapted from various scholars to measure the complete process of political socialization of youth. The results of the measurement model show that the out of 51 items 42 items are with loadings greater than 0.50. In applying PLS-SEM, the measurement model gives assurance that indicators have a strong relationship with their corresponding latent constructs. Also, items show the convergent and discriminant validity of corresponding constructs. The implication of the measurement model results proved that PLS will assist communication and media studies that are designed as exploratory studied that will lead to theory building.
\end{abstract}

Keywords: Partial Least Squares (PLS), measurement model, media and communication, validity and reliability.

\section{Introduction}

Unlike other marketing and behavioral studies, media and communication studies contain complex modelling to understand the phenomena. Hence such complex modelling requires a higher level of analysis. Such requirements led to the emergence and development of structural equation modelling (SEM). SEM is known as second-generation technique. This has mainly two sub techniques: The Covariance Based (CB-SEM) and the Variance Based (PLS-SEM). The former has been commonly applied for confirmatory or explanatory research. In other words, it is a preferred technique "when the aim is theory testing, theory confirmation or the comparison of alternative theories" (Hair et al., 2014). Contrary later has been applied when the "theory is less developed" such as exploratory research (Hair et al., 2014). Though, both have extensive, scalable and flexible causal-modelling capabilities (Lowry, Gaskin, 2014). But, these two techniques have different assumption at statistical analysis (Memon et al., 2017).

The covariance-based SEM has a strict condition of normality of data distributions, smallest sample size, and maximum model complexity (Hair et al., 2014) whereas variance-based (PLS) SEM has flexibility data. Having all these superior capabilities, however, it still does not

\footnotetext{
${ }^{*}$ Corresponding author

E-mail addresses: mramzan@usindh.edu.pk (M.R. Pahore)
} 
undermine the need for first-generation techniques (Lowry, Gaskin, 2014). Conversely, PLS-SEM shows its potentials in handling the complex cause-effect structural models. This complexity of cause-effect structural models with formative constructs, or a combination of both reflective and formative constructs or may have many endogenous, exogenous, moderating or mediating can be established using PLS-SEM. However, Partial least squares (PLS) SEM have a lot of proposal for communication and behavioral scholars. Nonetheless, literature "may distract behavioral and communication researchers from the relatively simple logic of PLS, dissuade them from selecting the technique, or worse, cause them to misappropriate the technique" (Lowry, Gaskin, 2014).

Therefore, this study will answer to this call by applying Partial Least Squares SEM to test the reliability of the measures (manifest variable) selected for the current study, and also establish the convergent validity and discriminant validity of the latent constructs. Hence, before analyzing data in PLS-SEM, we have to ensure that the data have no missing values; data is free of outliers and can stand the process of reliability and validity test (Hair et al., 2014).

The argument for Partial Least Squares SEM as a feasible approach is achieving acceptance all over several disciplines. Many researchers in business communication, marketing and management information systems have published studies within their respective fields (Joe et al., 2014; Hair et al., 2012). However, PLS-SEM is hardly applied in the field of media and communication studies (Lowry, Gaskin, 2014). This perhaps increased the tension among the scholars in the adoption of PLS-SEM in media and communication fields. As it holds back media and communication researcher from deeper understanding and testing of complete theoretical models which explains media and communication research phenomenon (Lowry, Gaskin, 2014). Although most of the proven theoretical models are too complex to be tested with traditional statistical techniques, still media and communication researcher use the traditional technique to test the "parts" of models without examining the "big picture" of the theoretical model (Lowry, Gaskin, 2014). Therefore, communication scholars lament that the infrequent adoption of PLS in media and communication fields holds back media and communication studies from deeper understanding and testing of "big picture" of the underlying phenomena.

In the same vein, Memon, Ting, Ramayah, Chuah, and Cheah, (Ting et al., 2017) claimed that the student who is perusing their $\mathrm{PhD}$ has some issue concerning the selection of the analysis method. This is a similar case in Pakistan; many scholars are still using conventional regressionbased tools for data analysis. Often time, this leads to the pointless procedure, misleading findings and misinformed decisions (Memon et al., 2017). These authors attempt to contribute to understanding the power PLS-SEM as a tool of statistical analysis and its capabilities to contribute to theory building. Although, media and communication scholars are interested in how their data explains the real situation of phenomena through the hypothesized model (Hair et al., 2012, 2014). To examine this, the researcher needs to follow certain process and requirements to analyses variables (IVs, DVs, Mediators, or moderator) and coefficient path (direct and indirect), particularly manifest variable (observed) and its latent variable (unobserved). Hence, before testing the hypothesized relationships (structural model), the instrument must be validated and reliability must be established. Hence, the current study is examining an instrument of political socialization through family, classroom, peers and use of informational media for political knowledge and political participation. Therefore, the adapted measures, such as six items of the family communicative environment were adapted from Austin and Nelson (Nelson, 1993), five items of classroom activities and eight items of Interpersonal Communication were adopted from (Kwon et al., 2014). One item for measuring peer surveillance norms (valuing knowledge) and five items for measuring the peer importance to political behaviour (Lee et al., 2013; Zhou, 2009) were adopted to measure peer norms. Moreover, to measure the informational media use, Pasek, Kenski, Romer, and Jamieson (Pasek et al., 2006) scale was adopted, ten items for measuring the political knowledge from (Fraile, 2011), lastly, ten items for measuring the political participation were adopted from Jung, Kim, and de Zúñiga (Jung et al., 2011) respectively. Hence, the current study has an opportunity to confirm the reliability and validity of the adopted or adapted variables from the various authors through PLS-SEM approach. To do so, PLS-SEM offers the potential process referred to as a measurement model. This study proposed a research question how well do the adopted or adapted items from different scholars employed in this research perform when subjected to reliability and validity test in the context of Partial Least Squares PLS?

In addition, this study contains following main variables: Family Communicative Environment: This variable is the first agent of political socialization measures adopted from 
Austin and Nelson (Austin, Nelson, 1993). This construct refers to an open discussion climate in the home, where youth feel free to talk about political and social issues with family members. Respondent was asked to indicate their level of the agreement through a 7- point Likert Scale ( $1=$ Strongly Disagree to $7=$ strongly agree).

Classroom Activities: This refers to the activities in which youth may experience certain types of societal and political behaviour in the classroom. Such as "discussions or debating political or social issues, participating in political role-playing, learning about how government works, following the news as part of a class assignment and being encouraged to make up their mind about issues" were asked by using the 7- points Likert Scale (1=Strongly Disagree to 7= strongly agree).

Peer norms: This refer to youth perception about their friends as valuing knowledge about current affairs as well as giving importance to political activities (Azis et al., 2020; Mohamad et al., 2018) to measure this construct one item from Lee et al. (2013) and five items from Zhou (Zhou, 2009) were adapted. Although, they measured through the separate question as valuing knowledge (Lee et al., 2013) and valuing political behaviour (Zhou, 2009). But this study intends to measure both valuing information and political activities collectively thus both questions were merged and measured on 7-points Likert Scale ( $1=$ Strongly Disagree to $7=$ strongly agree).

Informational media: This variable use refers to youth media consumption behaviour such as watching or reading news content from online and offline media (Earl et al., 2017). Here this study assessed the frequency with which youth use the following three types of information sources, "national (TV news and newspapers) and local (TV news and newspapers) and online newspaper via web sites of mainstream news organizations". The responses are in Likert scale having 7 -point of ( $1=$ never to $7=$ every time).

Interpersonal communication: This construct was used as a mediating variable in this study between informational media use and political knowledge for political participation. Thus this construct refers to youth's talk (face-to-face and online messaging) about political and social issues with their family, friend and outsiders. This measure was adopted from Kwon, Wilcox, and Shah (Kwon et al., 2014), which consist of eight questions. A 7-point Likert scale asking respondent to indicate the frequency of political talk ( $1=$ Never to $7=$ every time).

Political knowledge: This construct was also used as a mediating variable between interpersonal communication and political participation (Banducci et al., 2017; Zuniga, Diehl, 2019). This second last construct consists of ten items on factual political information about government institutions (e.g. provisional assembly and how things operate there), about leaders and their positions as well as policies and its importance (Fraile, 2011; Stadelmann et al., 2018). Hence, such factual knowledge they gain in home, classroom setting, from friends, and also from news media (Pontes et al., 2019). This construct has five responses, which includes four multiplechoice answers and the fifth one was do not know option (Fraile, 2011). Moreover, incorrect answers and don't know the response will be analyzed through the conventional index (Mondak, 1999). It refers to count just the total number of correct answers. For analysis, all items were summed to form a composite index ranging from o (no correct answers) to 10 (Elhadadi, 2019; Dimitrova et al., 2014).

Political Participation: Political knowledge, socialization or self-efficacy appears to be strong indication of online/offline political participation (Valenzuela et al., 2019; Valenzuela et al., 2018). Hence, political participation is the dependent variable in this study. For measuring political participation, Jung, Kim, and de Zúñiga (Jung et al., 2011) scale were adapted. They asked respondents if during the past 2 years they had engaged or not in conventional such as whether respondents voted in 2008 presidential election and non-conventional political activities like "attended a political meeting, or rally, work for a political party or candidate, wore a campaign T-shirt or cap, called or sent a letter to elected public officials". Although responses to each statement were yes or no, which is fundamentally nominal or categorical (discrete at measurement level) measurement scale (Scheufele et al., 2006). Hence, PLS-SEM has advantages for such data therefore, all items were summed to form an additive index ranging from $\mathrm{o}$ (no correct answers) to 10 in SPSS. Hence it became only one item to be tested in PLS-SEM. Thus, emerging instruments from these measures were subjected to quality test through expert validation and reliability and validity test in PLS (Hair et al., 2014). 


\section{Materials and methods}

Missing Data: Before testing the reliability and validity of measures in PLS-SEM, the data were checked for missing values (Hair et al., 2014). Accordingly, to treat these missing values, initially, Hair et al. (2014) suggestions were followed. Firstly, questionnaires exceed $15 \%$ missing values were excluded from the analysis for this study. Secondly, if the high portion of responses for a single construct is not given by respondents, hence such observation was also removed. Subsequently, having less than $5 \%$ missing values in indicators were replaced using mean substitution (Hair et al., 2010: 61).

Outliers: For identifying the extreme response to a specific item or extreme responses to all items in the study, a common technique Mahalanobis distance was used to detect outliers. Subsequently, six outliers were discovered and consequently were removed from the data file because these outliers can disturb the correctness of data analysis technique (Kura, 2014). Consequently, after deleting six multivariate outliers, the actual questioners in the current study were 288.

Normality Test: The previous study (Wetzels et al., 2009) has conventionally supposed that PLS-SEM gives correct model estimations in states of extremely non-normal data. Nevertheless, such assumption proved to be wrong. In recent times, Hair, Sarstedt, Ringle and Mena (Hair et al., 2012) advised that studies must check the normality of the data. Because, "highly skewed or kurtotic data can inflate the bootstrapped standard error estimates" (Chernick, 2008). Consequently, decrease the statistical power, which is particularly problematic for PLS-SEM's tendency to underestimate structural model relationships (Wold, 1982 as cited in Hair et al., 2012).

For this reason, it was necessary to inspect for the normality of collected data through graphics (Tabachnick, Fidell, 2007). The visual technique was picked against the statistical method because; Field (Field, 2009) asserted that if a study has a large sample of 200 or more, in this case, a researcher should "look at the shape of the distribution visually rather than looking at the value of the skewness". Accordingly, for the current study sample size (288) is above the 200, hence this justified the reason for employing the visual method for assessing the normality of collected data. Also, Hair et al. (Hair et al., 2014: 54) emphasize to examine two measures of distributions: skewness and kurtosis. Subsequently, a histogram and normal probability plots were examined to make sure that normality assumptions were not violated. Hence the collected data for the current study follow a normal pattern which means that the normality assumptions were not failed.

After identifying and treating the missing values, outliers and checking for the normality assumption of data, next, quality of data was examined by assessing the measurement model. Hence this assessment process involves internal consistency reliability test; convergent reliability and discriminant validity.

\section{Discussion}

The current findings of this study show that the measurement items have factorial validity with their variables. Hence, it demonstrates the assessment of measurement model (Shmueli et al., 2019), which involves internal consistent reliability, composite reliability and average variance, has explained by the measurement items to their latent constructs (Hair et al., 2019). Each item has reached its recommended levels (0.50). Specifically, 6 items submitted for the family communicative environment (Shah et al., 2017; Kim, 2019; Cornejo et al., 2020), only 4 items have loadings above 0.50 . Similarly, classroom activities originally have 5 items but only 4 of them with loadings above 0.50 were retained (Ohme et al., 2020). For the construct measuring peer norms, out of 6 only 3 have loading above 0.50 thresholds. Similarly, out of 5 items, only 4 items were retained for the informational media use. Among the 8 measurement items submitted for the interpersonal communication (Andersen, Hopmann, 2018), 6 of them load above 0.50 threshold. Hence, 10 items of political knowledge were combined to form an additive index (Stadelmann et al., 2018), which in results we got only one item for political knowledge thus that have loading above 0.50 threshold. Similarly, 11 items of political participation were combined to form composite index (Dimitrova et al., 2014; Hair et al., 2019), which results in only one item for political participation thus load above 0.50 threshold. Above all, out of 51 measurement items 42 items are with factor loadings greater than 0.50 .

Also, the results of the constructs of the model show that both convergent and discriminant validity is established. Therefore, the model gives assurance that it is suitable for measuring the 
relationship between political socialization agents (Family, Classroom, and Peers), media, and political participation. By the large, PLS-SEM (Khan et al., 2019) can be used for the next level of assessment through the process of a structural model. By doing so, this will demonstrate the predictive validity of the model as well as the ability of the independent variable (informational media use) to explain the average variance of the dependent variable (Political Participation) (Hair et al., 2020).

\section{Results}

Measurement model determines relationship pattern existing between the observed (items) and their corresponding unobserved (latent constructs) variables in PLS-SEM. Thus, these construct modelling can be in the reflective or formative model. The main difference between these both is that the indicators in the reflective model respond to changes in the construct which mostly leads variations in the indicators. Whereas, informative measurement model assumed that the variable is caused by the assigned items. Hence this study has only reflective measures. Reflective measurement model's indicators (items) are interchangeable since they share common variance. Thus, this interchangeability of measures permits the scholars to focus on the assigned indicators of interest while measuring the variables (Hair et al., 2012; 2014; Henseler et al., 2009). It indicates that in reflective measurement models, the exclusion or inclusion of indicators will not necessarily lead to non-reliability or impair the validity of the construct. Hence, Hair et al. (Hair et al., 2014) suggest that in reflective models causality is assumed that the items are caused by the assigned variables.

Since an analysis in PLS-SEM involves mainly two-step assessment: assessment of measurement model and assessment of structural model (Henseler et al., 2009). Hence this study aims to check the quality of data; therefore, measurement model was assessed for reflective constructs. To do so, the firstly individual item reliability was assessed as:

Individual Item Reliability: Individual item reliability was evaluated by investigative the outer loadings of each variable's items (Duarte, Raposo, 2010; Hair et al., 2012; Hair et al., 2014). Nevertheless, for interpreting the item reliability Afthanorhan (Afthanorhan, 2013) recommendations were followed, the outer loadings below 0.50 were deleted. This is because; those items contribute less towards the factors. Yet some items were deleted (FCE1, FCE6, CA4, $\mathrm{PN}_{3}$, PN2, PN, IMU5, IC1, and IC6). As a result, out of 51 items 9 items were deleted which resulting in the 42 items with factor loadings greater than 0.50 .

Accordingly, most of the items in Table 1 had relatively good loadings; the minimum 0.601 and maximum 0.845 loadings were observed for the items Table 1.

Table 1. Loadings, Composite Reliability and Average Variance Extracted

\begin{tabular}{llll}
\hline Latent constructs and indicators & Loadings & AVE & $\begin{array}{l}\text { Composite } \\
\text { Reliability }\end{array}$ \\
\hline Family Communicative Environment & & 0.547 & 0.827 \\
FCE & 0.662 & & \\
FCE2 & 0.845 & & \\
FCE3 & 0.754 & & \\
FCE4 & 0.683 & & \\
FCE5 & & 0.542 & 0.824 \\
Classroom Activities CA & 0.836 & & \\
CA1 & 0.766 & & \\
CA2 & 0.610 & & \\
CA3 & 0.714 & & \\
CA5 & & 0.519 & 0.761 \\
\hline Peer Norms & 0.745 & & \\
PN4 & 0.799 & & \\
PN5 & 0.601 & & \\
PN6 & & & \\
\hline
\end{tabular}




\begin{tabular}{llll}
\hline Informational Media Use & & 0.589 & 0.851 \\
IMU1 & 0.732 & & \\
IMU2 & 0.689 & & \\
IMU3 & 0.828 & & \\
IMU4 & 0.813 & & \\
\hline Interpersonal Communication & & 0.502 & 0.858 \\
IC2 & 0.755 & & \\
IC3 & 0.723 & & \\
IC4 & 0.721 & & \\
IC5 & 0.643 & & \\
IC7 & 0.725 & & \\
IC8 & 0.679 & & \\
\hline Political Knowledge & & 1.000 & 1.000 \\
PK_Sum & 1.000 & & \\
\hline Political Participation & & 1.000 & 1.000 \\
PP_Sum & 1.000 & & \\
\hline
\end{tabular}

Internal Consistency Reliability: Although, Cronbach's alpha coefficient and composite reliability coefficient are the most frequently preferred evaluator for internal consistency reliability of the questionnaire. Hence for the current research, the composite reliability coefficient was selected to determine the internal consistency reliability of adapted items.

Conversely, there are mainly two reasons to select composite reliability coefficient than the Cronbach's alpha coefficient. First of all, composite reliability coefficient results are much less unfair estimate of reliability than Cronbach's alpha coefficient. Since the former assumes that all indicators are equally reliable to their variable without taking it to the real contribution of an individual item loading (Hair et al., 2014). Whereas, composite reliability coefficient undertakes that all items have different outer loadings to its variable.

Secondly, Cronbach's alpha tends to undervalue the internal consistency reliability (Hair et al., 2014). Hence, Bagozzi and Yi (Bagozzi, Yi., 1988) and Hair et al (Hair et al., 2011) recommendation were followed, the internal consistency reliability using composite reliability coefficient were at least 70 or more. Hence, as presented in Table 1 , the composite reliability coefficient of every variable ranged from 1.000 to 0.761 , with each exceeding the minimum acceptable level of .70.

Convergent Validity: After checking for the reliability of measures, subsequently, it's time to determine the validity of indicators under study. Convergent validity is the first step to check for the validity of items. Hence, it is the degree to which items suitably indicate the proposed variable and correlate with other items of the same variable (Hair et al., 2006). To determine this validity we examine Average Variance Extracted (AVE) of each latent variable under study (Fornell, Larcker, 1981). The value for achieving adequate convergent validity, Chin (Chin, 1998) recommended that the AVEs of each latent construct must be at least $>.50$ or more. Hence, following Chin (Chin, 1998) recommendation, the AVEs values presented in Table 1 are high loadings $(>.50)$ on their respective variables, thus indicating adequate convergent validity.

Discriminant Validity: Similar to the convergent validity, this type of validity (discriminate validity) was also determined using Average Variance Extracted (AVE) (Fornell, Larcker, 1981). But, discriminate validity was evaluated by comparing the correlations among the latent variables with square roots of AVE (Fornell, Larcker, 1981). Hence, following the rule for evaluating discriminant validity, firstly, Fornell and Larcker (Fornell, Larcker, 1981) recommended the use of AVE with a score of .50 or more. Secondly, they also recommended that the square root of the AVE should be greater than the correlations among latent variables.

Also, discriminant validity was assessed by following Chin's (Chin, 1998) criterion by comparing the indicator loadings with other reflective indicators Table 3. 
Table 2. Latent constructs Correlations and Square Roots of Average Variance Extracted (Fornell and Larcker criterion)

\begin{tabular}{|c|c|c|c|c|c|c|c|c|c|}
\hline \multicolumn{3}{|c|}{ Latent Constructs } & 1 & 2 & 3 & 4 & 5 & 6 & 7 \\
\hline \multicolumn{3}{|c|}{ Classroom Activities } & \multicolumn{7}{|l|}{0.736} \\
\hline \multicolumn{3}{|c|}{$\begin{array}{l}\text { Family Communicative } \\
\text { Environment }\end{array}$} & 0.412 & 0.739 & & & & & \\
\hline \multicolumn{3}{|c|}{$\begin{array}{l}\text { Interpersonal } \\
\text { Communication }\end{array}$} & 0.228 & 0.221 & 0.709 & & & & \\
\hline \multicolumn{3}{|c|}{ Informational Media Use } & 0.279 & 0.331 & 0.382 & 0.767 & & & \\
\hline \multicolumn{3}{|c|}{ Political Knowledge } & 0.041 & 0.023 & $\begin{array}{l}- \\
0.074\end{array}$ & 0.085 & 1.000 & & \\
\hline \multicolumn{3}{|c|}{ Peer Norms } & 0.245 & 0.310 & 0.314 & 0.340 & -0.072 & \multicolumn{2}{|l|}{0.720} \\
\hline \multicolumn{3}{|c|}{ Political Participation } & -0.135 & 0.087 & 0.179 & 0.063 & -0.055 & 0.136 & 1.000 \\
\hline \multicolumn{10}{|c|}{$\begin{array}{l}\text { Note: Values shown in boldface represent the square root of the average variance extracted (AV] } \\
\text { Hence, as indicated in Table 2, the values of the AVEs ranged between } 0.502 \text { and 1.oo } \\
\text { demonstrating the adequate values. Also in Table 2, the correlations among the latent variabl } \\
\text { were compared with the square root of the AVEs (average variances extracted) (values } \\
\text { boldface). Moreover, Table } 2 \text { also illustrating that the square root of the AVEs were all great } \\
\text { than the correlations among latent variables, thus indicating adequate discriminant validity } \\
\text { achieved (Fornell, Larcker, 1981). } \\
\text { Moreover, to get adequate discriminant validity, Chin (Chin, 1998) advises that all th } \\
\text { indicator loadings should be higher than the cross-loadings in the table. Hence, all indicators } \\
\text { presented (with boldface) were higher than the cross-loading, thus demonstrating adequa } \\
\text { discriminant validity is achieved. }\end{array}$} \\
\hline \multicolumn{10}{|c|}{ Table 3. Cross Loadings (Chin criterion) } \\
\hline & $\mathrm{CA}$ & FCE & IC & & IMU & $\mathrm{PK}$ & $\mathrm{PN}$ & & PP \\
\hline CA1 & 0.836 & 0.310 & 0.1 & & 0.216 & 0.111 & 0.18 & & -0.168 \\
\hline CA2 & 0.766 & 0.231 & 0.1 & & 0.192 & 0.009 & 0.12 & & -0.109 \\
\hline CA3 & 0.610 & 0.285 & 0.2 & & 0.145 & -0.068 & 0.25 & & -0.024 \\
\hline CA5 & 0.714 & 0.386 & 0.1 & & 0.249 & 0.020 & 0.19 & & -0.067 \\
\hline FCE2 & 0.308 & 0.662 & 0.1 & & 0.178 & 0.033 & 0.26 & & 0.138 \\
\hline FCE3 & 0.330 & 0.845 & 0.2 & & 0.332 & 0.067 & 0.24 & & 0.082 \\
\hline $\mathrm{FCE}_{4}$ & 0.297 & 0.754 & 0.1 & & 0.191 & -0.100 & 0.21 & & -0.004 \\
\hline $\mathrm{FCE}_{5}$ & 0.289 & 0.683 & $0 . c$ & & 0.233 & 0.022 & 0.19 & & 0.031 \\
\hline IC2 & 0.166 & 0.231 & 0.7 & & 0.457 & -0.035 & 0.27 & & 0.160 \\
\hline
\end{tabular}




\begin{tabular}{llllllll}
\hline IC3 & 0.283 & 0.192 & 0.723 & 0.264 & -0.071 & 0.195 & -0.004 \\
IC4 & 0.231 & 0.199 & 0.721 & 0.211 & -0.090 & 0.292 & 0.118 \\
IC5 & 0.168 & 0.130 & 0.643 & 0.188 & -0.078 & 0.218 & 0.098 \\
IC7 & 0.083 & 0.042 & 0.725 & 0.176 & -0.080 & 0.157 & 0.133 \\
IC8 & 0.025 & 0.064 & 0.679 & 0.138 & 0.022 & 0.138 & 0.243 \\
IMU1 & 0.278 & 0.358 & 0.228 & 0.732 & 0.031 & 0.261 & -0.043 \\
IMU2 & 0.194 & 0.155 & 0.245 & 0.689 & 0.053 & 0.168 & 0.030 \\
IMU3 & 0.191 & 0.181 & 0.342 & 0.828 & 0.062 & 0.250 & 0.105 \\
IMU4 & 0.195 & 0.295 & 0.344 & 0.813 & 0.106 & 0.335 & 0.092 \\
PK & 0.041 & 0.023 & -0.074 & 0.085 & 1.000 & -0.072 & -0.055 \\
PN4 & 0.218 & 0.248 & 0.134 & 0.254 & -0.049 & 0.745 & 0.021 \\
PN5 & 0.175 & 0.260 & 0.325 & 0.261 & -0.107 & 0.799 & 0.152 \\
PN6 & 0.136 & 0.154 & 0.197 & 0.217 & 0.012 & 0.601 & 0.110 \\
PP & -0.135 & 0.087 & 0.179 & 0.063 & -0.055 & 0.136 & 1.000 \\
\hline
\end{tabular}

\section{Conclusion}

Generally, this research aims to give a practical exhibition and explanation of the PLS approach for assessing the reliability and validity of questions and its variables in the situated learning theory and communication mediation model. The motivation of carrying this research is the observation Memon et al. (Memon et al., 2017) that there is the issue of selection of analysis method to the PhDs that lead to the meaningless procedure, misleading findings and misinformed decisions. Also, Gaskin and Lowry (Gaskin, Lowry, 2014) recommendation is followed to apply PLS-SEM in media communication studies because of its inconsistent usage and lack of appreciation in media and communication studies. Hence, this study proves the potential of PLS-SEM approach for data analysis compare to regression analysis and its covariance-based structural equation modelling. This is because, firstly, as some variables (political knowledge and political participation) have single-item measures, and other variables (family communicative environment, classroom activities, peer norms, informational media use, and interpersonal communication) have multiple-item measures, the combination of different scales of measurement in this research (nominal and interval) made PLSSEM potential for this study compare to covariance-based structural equation modelling. Thus, this made ideal for the current study. Secondly, PLS-SEM is used for similar function with regression analysis and its covariance-based structural equation modelling. However, PLS-SEM is distributionfree analysis approach which performs well when data not normal. Thirdly, in exploratory research like the one in this study, PLS-SEM recommends simple but robust options. By applying PLS-SEM (Ringle et al., 2020), the results allow the scholar to show that the specified model relationship contains manifest variable (observed), have a strong relationship with its latent variable (unobserved). Also, results show convergent and discriminant validity of the latent variable. The current research implies that PLS will assist communication and media studies scholars who are intended to conduct exploratory research for theory building.

\section{References}

Afthanorhan, 2013 - Afthanorhan, W.M.A.B.W. (2013). A comparison of partial least square structural equation modeling (PLS-SEM) and covariance based structural equation modeling (CB-SEM) for confirmatory factor analysis. International Journal of Engineering Science and Innovative Technology. 2(5): 198-205. 
Andersen, Hopmann, 2018 - Andersen, K., Hopmann, D.N. (2018). Compensator, amplifier, or distractor? The moderating role of informal political talk on the effect of news media use on current-affairs learning among first-time voters. Political Communication. 35(4): 634-654.

Austin, Nelson, 1993 - Austin, E.W., Nelson, C.L. (1993). Influences of ethnicity, family communication, and media on adolescents' socialization to US politics. Journal of Broadcasting \& Electronic Media. 37(4): 419-435.

Azis et al., 2020 - Azis, H., Pawito, P., Setyawan, A. (2020). The impact of new media use on youth political engagement. International Journal of Multicultural and Multireligious Understanding. $7(1)$ : 223-233.

Bagozzi, Yi, 1988 - Bagozzi, R.P., Yi, Y. (1988). On the evaluation of structural equation models. Journal of the academy of marketing science. 16(1): 74-94.

Banducci et al., 2017 - Banducci, S., Giebler, H., Kritzinger, S. (2017). Knowing more from less: How the information environment increases knowledge of party positions. British Journal of Political Science. 47(3): 571-588.

Chernick, 2008 - Chernick, M. R. (2008). Bootstrap methods: a guide for practitioners and researchers. Hoboken.

Chin, 1998 - Chin, W.W. (1998). The partial least squares approach to structural equation modeling. Modern methods for business research. 295(2): 295-336.

Cornejo et al., 2020 - Cornejo, M., Rocha, C., Castro, D., Varela, M., Manzi, J., González, R. Livingstone, A.G. (2021). The intergenerational transmission of participation in collective action: The role of conversation and political practices in the family. British Journal of Social Psychology. 60(1): 29-49.

Dimitrova et al., 2014 - Dimitrova, D.V., Shehata, A., Strömbäck, J., Nord, L.W. (2014). The effects of digital media on political knowledge and participation in election campaigns: Evidence from panel data. Communication Research.41(1): 95-118. DOI: 10.1177/0093650 211426004.

Duarte, Raposo, 2010 - Duarte, P.A.O., Raposo, M.L.B. (2010). A PLS model to study brand preference: An application to the mobile phone market. In Handbook of partial least squares. Springer Berlin Heidelberg: 449-485.

Duarte, Raposo, 2017 - Earl, J., Maher, T.V., Elliott, T. (2017). Youth, activism, and social movements. Sociology Compass. 11(4): e12465.

Elhadidi 2019 - Elhadidi, M.A.F. (2019). Facebook credibility: Evidence from online and offline political participation, political contribution, and platform efficacy. Global Media Journal. 17(32): 1-11.

Field, 2009 - Field, A. (2009). Discovering statistics using SPSS (3rd ed). London: Sage Publications.

Fornell, Larcker, 1981 - Fornell, C., Larcker, D. (1981). Structural Equation Models with Unobservable Variables and Measurement Error. Journal of Marketing Research. 18(3): 39-50.

Fraile, 2011 - Fraile, M. (2011). Widening or reducing the knowledge gap? Testing the media effects on political knowledge in Spain (2004-2006). The International Journal of Press/Politics. 16(2): 163-184. doi: 10.1177/1940161210388413.

Hair et al., 2012 - Hair, J.F., Sarstedt, M., Ringle, C.M., Mena, J.A. (2012). An assessment of the use of partial least squares structural equation modeling in marketing research. Journal of the academy of marketing science. 40(3): 414-433.

Hair et al., 2014 - Hair, J.F., Hult, G.T.M, Ringle, C.M., Sarstedt, M. (2014). A Primer on partial least squares structural equation modelling (PLS-SEM). London: Sage Publications.

Hair et al., 2019 - Hair, J.F., Risher, J.J., Sarstedt, M., Ringle, C.M. (2019). When to use and how to report the results of PLS-SEM. European Business Review.

Hair et al., 2020 - Hair Jr, J.F., Howard, M.C., Nitzl, C. (2020). Assessing measurement model quality in PLS-SEM using confirmatory composite analysis. Journal of Business Research. 109: 101-110.

Henseler et al., 2009 - Henseler, J., Ringle, C.M., Sinkovics, R.R. (2009). The use of partial least squares path modeling in international marketing. In New challenges to international marketing. Emerald Group Publishing Limited: 277-319. 
Joe et al., 2014 - Joe Jr, F., Sarstedt, M., Hopkins, L., Kuppelwieser, V.G. (2014). Partial least squares structural equation modeling (PLS-SEM): An emerging tool in business research. European Business Review. 26(2): 106-121.

Jung et al., 2011 - Jung, N., Kim, Y., de Zúñiga, H.G. (2011). The mediating role of knowledge and efficacy in the effects of communication on political participation. Mass Communication and Society. 14(4): 407-430. DOI: 10.1080/15205436.2010.496135.

Khan et al., 2019 - Khan, G.F., Sarstedt, M., Shiau, W.L., Hair, J.F., Ringle, C.M., Fritze, M.P. (2019). Methodological research on partial least squares structural equation modeling (PLS-SEM). Internet Research.

Kim, 2019 - Kim, M. (2019). Parental influence on adolescent preference for television public affairs content: A South Korean panel study. Journalism \& Mass Communication Quarterly. 96(2): 497-515.

Kwon et al., 2014 - Kwon, M.W., Wilcox, D., Shah, D.V. (2014). The Role of recreational media use in youth socialization: extending the citizen communication mediation model. Online Journal of Communication \& Media Technologies. 4(1): 185-215.

Lee et al., 2013 - Lee, N.J., Shah, D.V., McLeod, J.M. (2013). Processes of political socialization a communication mediation approach to youth civic engagement. Communication Research. 40(5): 669-697. DOI: 10.1177/0093650212436712

Lee et al., 2017 - Lee, F.L., Chen, H.T., Chan, M. (2017). Social media use and university students' participation in a large-scale protest campaign: The case of Hong Kong's Umbrella Movement. Telematics and Informatics. 34(2): 457-469.

Lowry, Gaskin, 2016 - Lowry, P.B., Gaskin, J. (2014). Partial least squares (PLS) structural equation modeling (SEM) for building and testing behavioral causal theory: When to choose it and how to use it. IEEE Transactions on Professional Communication. 57(2): 123-146.

Memon et al., 2017 - Memon, M.A., Ting, H., Ramayah, T., Chuahd, F., Cheah, J.-H. (2017). Review of the methodological misconceptions and guidelines related to the application of structural equation modeling: a malaysian scenario. Journal of Applied Structural Equation Modeling. 1(1): i-xiii.

Mohamad, et al., 2018 - Mohamad, B., Dauda, S.A., Halim, H. (2018). Youth offline political participation: Trends and role of social media. Jurnal Komunikasi: Malaysian Journal of Communication. 34(3): 192-207.

Mondak, 1999 - Mondak, J.J. (1999). Reconsidering the measurement of political knowledge. Political Analysis. 8(1): 57-82.

Ohme et al., 2020 - Ohme, J., Marquart, F., Kristensen, L.M. (2020). School lessons, social media and political events in a get-out-the-vote campaign: successful drivers of political engagement among youth? Journal of Youth Studies. 23(7): 886-908.

Pasek et al., 2006 - Pasek, J., Kenski, K., Romer, D., Jamieson, K.H. (2006). America's youth and community engagement how use of mass media is related to civic activity and political awareness in 14-to 22-year-olds. Communication Research.33(3): 115-135. DOI: $10.1177 / 0093650206287073$.

Ponteset al., 2019 - Pontes, A.I., Henn, M., Griffiths, M.D. (2019). Youth political (dis) engagement and the need for citizenship education: Encouraging young people's civic and political participation through the curriculum. Education, Citizenship and Social Justice. 14(1): 3-21.

Ringle et al., 2020 - Ringle, C.M., Sarstedt, M., Mitchell, R., Gudergan, S.P. (2020). Partial least squares structural equation modeling in HRM research. The International Journal of Human Resource Management. 31(12): 1617-1643.

Shah et al., 2017 - Shah, D.V., McLeod, D.M., Rojas, H., Cho, J., Wagner, M.W., Friedland, L.A. (2017). Revising the communication mediation model for a new political communication ecology. Human Communication Research. 43(4): 491-504.

Shmueli, et al., 2019 - Shmueli, G., Sarstedt, M., Hair, J.F., Cheah, J.H., Ting, H., Vaithilingam, S., Ringle, C.M. (2019). Predictive model assessment in PLS-SEM: guidelines for using PLS predict. European Journal of Marketing.

Stadelmann et al., 2018 - Stadelmann-Steffen, I., Sulzer, L. (2018). Just another brick in the wall? The relationship between classroom-based political education and the political interest of young adults in Switzerland. Journal of Youth Studies. 21(4): 550-573. 
Tabachnick, Fidell, 2007 - Tabachnick, B.G.., Fidell, L.S. (2007). Using Multivariate Statistics (5th ed). Boston, Massachusettes: Alllyn and Bacon/Pearson Education.

Valenzuela et al., 2018 - Valenzuela, S., Correa, T., Zuniga, H.G. (2018). Ties, likes, and tweets: Using strong and weak ties to explain differences in protest participation across Facebook and Twitter use. Political Communication. 35(1): 117.

Valenzuela et al., 2019 - Valenzuela, S., Halpern, D., Katz, J.E., Miranda, J.P. (2019). The paradox of participation versus misinformation: Social media, political engagement, and the spread of misinformation. Digital Journalism. 7(6): 802-823.

Wetzels et al., 2009 - Wetzels, M., Odekerken-Schröder, G., Van Oppen, C. (2009). Using PLS path modeling for assessing hierarchical construct models: Guidelines and empirical illustration. MIS Quarterly. 177-195.

Zhou, 2009 - Zhou, Y. (2009). The Role of communication in political participation: exploring the social normative and cognitive processes related to political behaviors. Ph.D. Dis. Washington State University.

Zuniga, Diehl, 2019 - Zuniga, H.G., Diehl, T. (2019). News finds me perception and democracy: Effects on political knowledge, political interest, and voting. New Media \& Society. 21(6): 1253-1271. 